\title{
Reproductive Bud Development of Pears (Pyrus communis L.) with Emphasis on the Bourse Shoot
}

\author{
L.P. Reynolds, G. Jacobs and K.I. Theron \\ Department of Horticultural Science \\ University of Stellenbosch \\ Private Bag X1 \\ Matieland, 7602 \\ South Africa
}

Keywords: bourse-over-bourse bearing, flower differentiation, flower initiation, 'Forelle', new-formed leaves, preformed leaves, reproductive bud, 'Rosemarie'

\begin{abstract}
For consistent yields in pear fruit production, knowledge of the development of the reproductive bud is required. The aim of this study was to gain more insight into the development of the primordial bourse shoot. The bourse shoot is important because of the ability of a bourse shoot to become reproductive, which can lead to bourse-over-bourse bearing. The progression of reproductive bud development in 'Forelle' and 'Rosemarie' was studied from primordial bourse shoot initiation until dormancy the following season. The primordial bourse shoot development in the reproductive bud before full bloom is poorly documented. The primordial bourse shoot was initiated in February 2003. The primordial bourse shoot development progressed during dormancy with a plastochron length of 60 to 80 days in June. The rate of preformed leaf formation increased rapidly until August, when the plastochron was 5 days. 'Rosemarie's' primordial bourse shoot development was more advanced at full bloom. This is one of the possible reasons for the higher bourse-over-bourse bearing habit of the cultivar. The number of leaves of the bourse shoot of 'Rosemarie' was significantly greater than with 'Forelle', which has a low tendency for bourse-over-bourse bearing. Flower initiation of the terminal bud of the bourse shoot was 56 and 77 days after full bloom for 'Forelle' and 'Rosemarie', respectively. Initiation was well correlated with the cessation of bourse shoot growth. An increase in mitotic activity occurred during flower differentiation of the terminal bourse bud, with a peak of floral appendage formation during December and January. From February until dormancy enlargement of the floral parts took place.
\end{abstract}

\section{INTRODUCTION}

Regular and substantial yields of superior quality fruit are the most important parameters for successful fruit growing. With a broader knowledge of the development of the reproductive buds these parameters should be easier to achieve. In the past, numerous scientists studied the development of the reproductive bud, but little emphasis was placed on the primordial bourse shoot. Luyten and De Vries (1924) dissected the mixed bud of 'Beurre Hardy' in December (Northern Hemisphere) and found vegetative points bearing 2 to 5 leaf primordia in the axils of the first two foliage leaves. These vegetative points can develop into bourse shoots. Walters (1968) also found primordial shoots or flowers in the leaf axils. He found that the primordial shoot could also form in the axils of the transitional leaves. The bourse is important for achieving regular yields because it is a potential bearing site.

The aim of this study was to determine when the bourse meristem and the primordial shoot develop and to follow its procession over time. The two cultivars that were used were 'Forelle' and 'Rosemarie'. They differ in their bearing habits. Whereas both cultivars bear mainly on spurs on two-year-old wood, 'Rosemarie' has the ability to bear fruit on one-year-old shoots, which can lead to bourse-over-bourse bearing (Du Plooy et al., 2002). By comparing the two cultivars it should be possible to get a better 
understanding of the bourse shoot development and the possible factors that increase bourse-over-bourse bearing.

\section{MATERIALS AND METHODS}

\section{Plant Material}

Reproductive buds or bourse shoots were collected from the Welgevallen Experimental Farm, situated in the Stellenbosch area of the Western Cape, South Africa

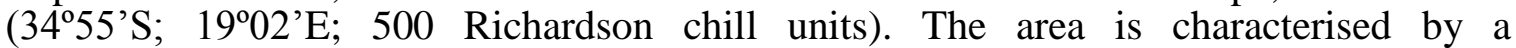
Mediterranean climate: cold, wet winters and warm, dry summers. 'Rosemarie' and 'Forelle' trees were used. 'Forelle' trees on quince rootstock with a 'Beurre Hardy' interstock were planted in 1998. 'Kieffer' was the cross pollinator at a density of $10 \%$. The 'Rosemarie' trees on BP1 rootstock were planted in 1992. 'Packham's Triumph' and 'Early Bon Chretien' were the cross pollinators at a density of $6.6 \%$ and $3.3 \%$, respectively. Trees are trained to a 3-wire-trellis central leader system.

\section{Data Recorded}

At 2-week intervals, from April 2002 to May 2003, five reproductive units per cultivar were sampled at random. Reproductive units were dissected and the following variables were recorded using a macroscope (Wild photo macroscope M 400, with a $64 \mathrm{x}$ enlargement): (1) the number of preformed leaves of the primordial bourse shoot and neoformed leaves of the bourse shoot, (2) the length of the longest bourse shoot leaf, (3) the length of the bourse shoot. During spring and summer (4) bud development of the bourse shoot was monitored and the time of flower initiation was recorded, (5) the rate of appendage formation in the bourse shoot terminal bud was calculated, (6) the bud scales, transitional leaves, true leaves and flowers were counted and (7) the size of the inflorescence was measured before dormancy.

Fifteen one-year-old reproductive units were tagged at random on 20 trees of each cultivar. These units varied from units bearing 1 to 3 fruit to units where all fruit had aborted. Some units had a well-developed bourse shoot, while others formed a bourse bud. The following data were recorded from these tagged units: (1) the number of fruit harvested in 2002 and 2003, and the sizes and seed content of these fruit, (2) the vegetative growth (bourse shoot) was measured and number of leaves counted and (3) the percentage of bourse shoots terminal meristem becoming reproductive was determined.

\section{RESULTS AND DISCUSSION}

In the 2002 season the primordial bourse shoot was detected in May 2002. It consisted of three leaves and the average length of the longest leaf was $3 \mathrm{~mm}$. In 2003 the primordial bourse shoot was first detected in January. It consisted of two leaves, with the average length of the longest leaf being 1mm (Fig. 1a). During dormancy (May until end of August) the development was generally slow, and the average number of leaves initiated in June was 0.5 and 0.38 for 'Rosemarie' and 'Forelle', respectively, resulting in a plastochron of 60 days for 'Rosemarie' and 80 days for 'Forelle'. With 'Rosemarie' there was an increase in leaf primordia initiation with a plastochron of 13 days, resulting in 2.38 leaves added. In the case of 'Forelle' the increase was only 0.66 with a plastochron of 47 days. This difference can possibly be attributed to a difference in chilling requirements between the two cultivars as 'Rosemarie' has a lower chilling requirement than 'Forelle'. In August the plastochron increased again for both cultivars to 5.31 and 6.86 for 'Rosemarie' and 'Forelle', respectively, resulting in an addition of 3.9 and 2.65 leaf primordia. Further development of the primordial bourse shoot was now mainly in terms of leaf enlargement and the leaf number remained more or less constant for the rest of the season. By 20 August the 'Rosemarie' and 'Forelle' had initiated 7.27 and 6.79 preformed leaves, respectively (Fig. 2). It seems that the cultivar with the higher tendency for bourse-over-bourse bearing, viz. 'Rosemarie', formed more preformed leaves than 'Forelle'. 
The leaves developed extensively during the dormancy period. The outer foliage leaves develop stipules (Luyten and De Vries, 1924) and these were first seen by the end of July at the base of the outer foliage leaves, while leaf hairs became more distinctive on the apical side of the leaf (Fig. 1b). The number of leaf hairs increased and before full bloom the leaves were completely covered with hairs. From two weeks before full bloom until two weeks after full bloom the rate at which the leaves enlarged increased exponentially (Fig. 3). Two weeks after full bloom the outer leaves had reached their final size and had probably become carbohydrate exporters (Faust, 1989). These carbohydrates are important for cell division and cell expansion. Cell division of pears continues until 9 weeks after full bloom (Westwood, 1978) and during this period the leaves of the bourse and the bourse shoot are responsible for supplying assimilates to the young fruits (Webster, 2000). For 'Forelle' the average number of new-formed leaves initiated after full bloom was 2.2 and for 'Rosemarie' 3.4 (Fig. 2). The difference can be attributed to the tendency for the 'Rosemarie' to form a bourse shoot whereas 'Forelle' normally only produces a bourse bud. This is also the main reason why bourse shoot growth cessation was three weeks earlier in 'Forelle' (data not shown).

Floral initiation in pears is characterised by the broadening of the apex, which becomes convex. The terminal buds of 'Forelle' bourse shoots initiated the reproductive bud 56 days after full bloom whereas in 'Rosemarie' this happened 77 days after full bloom (Fig 3). The time of initiation is correlated with bourse shoot growth cessation and because of the longer duration of bourse shoot growth in 'Rosemarie' initiation was later than in 'Forelle'. Westwood (1978) and Van Zyl (1979) made similar observations with flower initiation on spur shoots of pears. They stated that initiation is about sixty days after full bloom at the time of shoot growth cessation. Verheij (1996) observed in apple that the appearance of the dome-shaped meristem does not occur in all floral buds at once, but is spread over weeks. A similar observation was made in 'Rosemarie' and 'Forelle' in that initiation of the bourse shoot terminal buds was spread over a period of 5 weeks. Preceeding to the reproductive initiation, foliage leaves and transitional leaves developed. Verheij (1996) also observed a rapid increase in floral appendage formation in apple.

For both cultivars there was a rapid increase in appendage formation from initiation until the end of January (Fig. 4a). The average flower number counted before dormancy was 7 and 7.6 for the 'Rosemarie' and 'Forelle', respectively. Walters (1968) had observed a lower number of flowers for 'Bon Chretien' and 'Kieffer', and observed four flowers by the end of April (Southern Hemisphere). The lower number can be attributed to the differences in cultivars, different accumulation of chill units between the seasons or different cultural practices. The bourse shoot flower buds were largely completed at the start of dormancy. Tromp (2000) found similar results for the spur buds of pears. Verheij (1996) stated that the number of flowers per cluster varied only slightly with different environmental conditions, suggesting that this number is mainly genetically determined.

Floral differentiation refers to the morphological transformation of the apex leading to the formation of an inflorescence and it follows directly after initiation (Verheij, 1996). Differentiation is characterised by an increase in mitotic activity and in cell division. In addition, the rate of primordia production by the apex increases and bracts (leaf-forms in which the lamina and stipules are entirely suppressed) are formed (Bubán and Faust, 1982).

For the period from February to May the inflorescence, excluding the bract leaves, enlarged by $70-80 \%$ in both cultivars (Fig. $4 \mathrm{~b}$ ). This enlargement is mainly due to an enlargement in flower size, because the number of appendages remained approximately constant.

Of the two cultivars 'Rosemarie' has the ability to bear bourse-over-bourse (Du Plooy et al., 2002). In 'Rosemarie' the percentage tagged units bearing bourse-overbourse and flowering bourse-over-bourse but without setting fruit, was higher than in 'Forelle' (data not shown). 


\section{CONCLUSION}

In conclusion it can be said that the bourse shoot was initiated after all the flowers were formed at the end of January. This implies that in the reproductive bud hierarchy the bourse shoot followed after flower formation. Before and during dormancy the progression of the bourse shoot was slow, with the progression mainly in the formation of preformed leaves. After dormancy the preformed leaves enlarged rapidly and some newformed leaves were formed. The 'Rosemarie', with the higher tendency for bourse-overbourse bearing formed more preformed leaves than 'Forelle' (Fig. 2). Furthermore, the 'Forelle' developed a small number of new-formed leaves, which is in agreement with the cultivar's tendency to form bourse buds. On the other hand 'Rosemarie' developed a bourse shoot, which led to more new-formed leaves than in the case of 'Forelle'. Huet and Lemoine (1972) stated that the minimum number of leaves required for fruit to set is six, and from Fig. 2 we can see that the average number of leaves for 'Forelle', viz. eight leaves, was just above this critical number. In addition, Lauri and Térouanne (1999) found a positive relationship between leaf number and flowers in a flower cluster (flower quality) and also between leaf number and fruit set. Leaves are important for the developing flower because they act as a source of assimilates and hormones. Active leaves ensure that promotive substances produced elsewhere in the plant reach the developing bud.

'Forelle' bourse shoot growth cessation was 2 weeks before that of 'Rosemarie'. This led to earlier flower initiation, that was well correlated with bourse shoot growth cessation. Differentiation follows after initiation and all the flowers were formed by the end of January. From January until full bloom organ enlargement took place and the new bourse shoot was initiated.

\section{Literature Cited}

Bubán, T. and Faust, M. 1982. Flower bud induction in apple trees: Internal control and differentiation. Hort. Rev. 4: 174-203.

Carrera, M. 1982. Flower initiation in pear varieties. Acta. Hort. 124: 157-163.

Du Plooy, P., Jacobs, G. and Cook, N.C. 2002. Quantification of bearing habit on the basis of lateral bud growth of seven pear cultivars grown under conditions of inadequate winter chilling in South Africa. Sci. Hort. 95: 185-192.

Huet, J. and Lemoine, J. 1972. Etude des effects feuilles et des fruits sur I'induction florale des brachyblastes du poirier. Physiol. Végétale. 10: 529-545.

Faust, M. 1989. Physiology of Temperate Zone Fruit Trees. John Wiley and Sons Inc., New York: pp 169-229.

Lauri, P.E. and Terouanne, E. 1999. Effect of inflorescence removal on the fruit set of the remaining inflorescences and development of the laterals on one year old apple (Malus domestica Borkh.) branches. J. Hort. Sci. Biotech. 74(1): 110-117.

Luyten, I.D.A. and De Vries, L.I. 1924. Die periodiciteit van de knopontwikkeling bij den peer. Meded. Landb. Hoogesch. Wageningen. 15: 1-61.

Richardson, E.A., Schuyler, D.S. and Walker, D.R. 1974. A model for estimating the completion of rest for 'Redhaven' and 'Elberta' peach trees. Hort. Sci. 9(4): 331-332.

Tromp, J. 2000. Flower-bud formation in pome fruit as affected by fruit thinning. Pl. Gr. Regul. 31: 27-34.

Van Zyl, H.J. 1979. Vrugsetstudies met betrekking tot Pyrus communis, L., cultivar Packham's Triumph. PhD Thesis, University of Stellenbosch, Stellenbosch.

Verheij, F.A. 1996. Morphological and physiological aspects of the early phase of flower bud formation. PhD Thesis, Agricultural University Wageningen, Wageningen.

Walters, J.H. 1968. Die differensiasieverloop van reproduktiewe knoppe van Pyrus communis cv. Bon Chretien en Pyrus communis $\times$ Pyrus pyrifolia cv. Kiefer. MSc. Thesis, University of Stellenbosch, Stellenbosch.

Webster, A.J. 2002. Factors influencing the flower, fruit set and fruit growth of European pears. Acta Hort. 596(2): 699-709. 
Westwood, M.N. 1978. Temperate zone pomolgy: Physiology and culture, third edition, P01iland, Oregon: Timber Press.

\section{Figures}

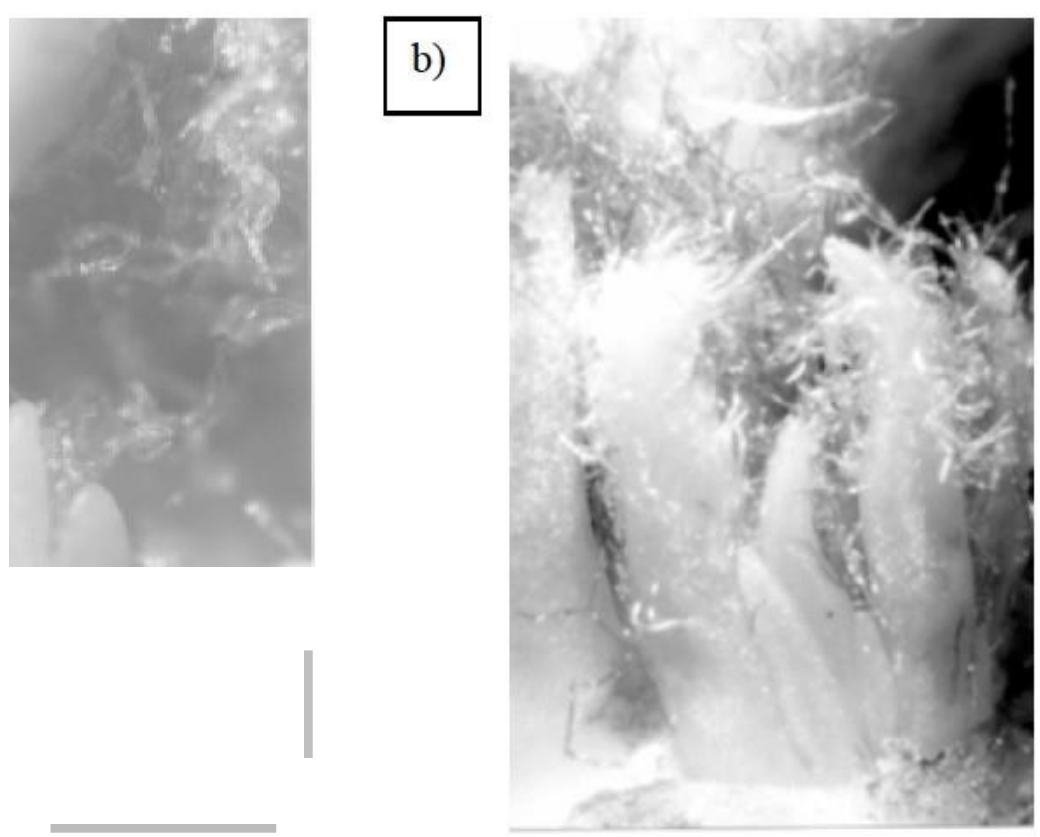

Fig. 1. (a) ('Rosemarie', $64 \mathrm{X}$ enlarged): First detection of the primordial bourse shoots at the end of Janualy 2003. The primordial bourse shoot consists of two leaves with an average length of $1 \mathrm{~mm}$ for the outer leaf. (b) Leaf stipules are seen at the base of the outer foliage leaves and leaf hairs become more distinct at the apical side of the outer leaves. ('Rosemarie', 16 July 2002, 20 X enlarged).

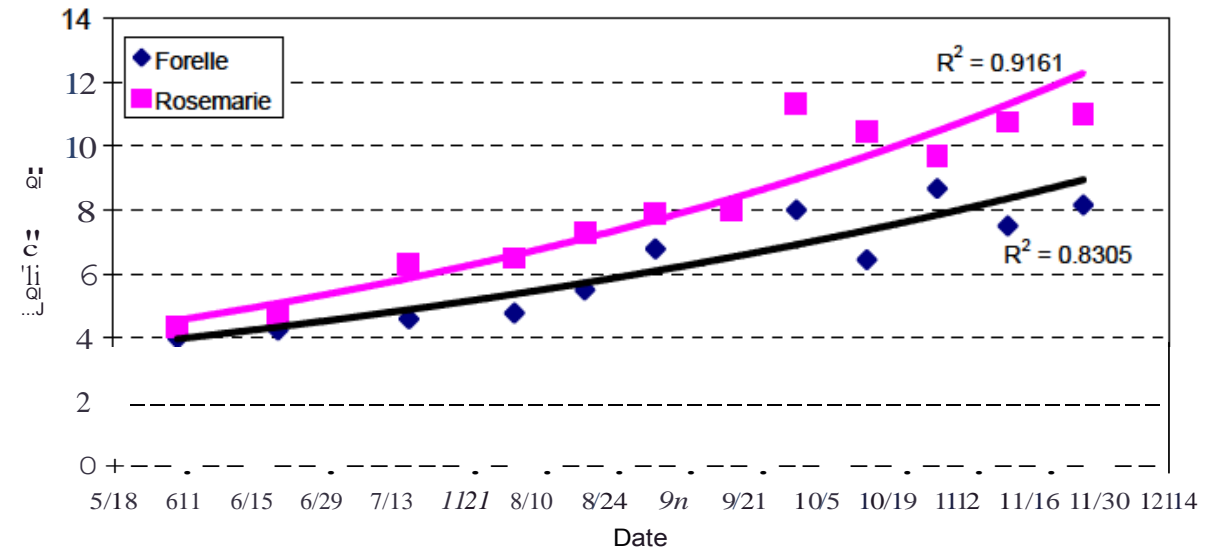

Fig. 2. Average number of bourse shoots leaves (pref01med as well as new-fonned) from time of primordial bourse shoot initiation lmtil bourse shoot growth cessation. Full bloom was 13 and 20 September for 'Rosemarie' and 'Forelle', respectively. 


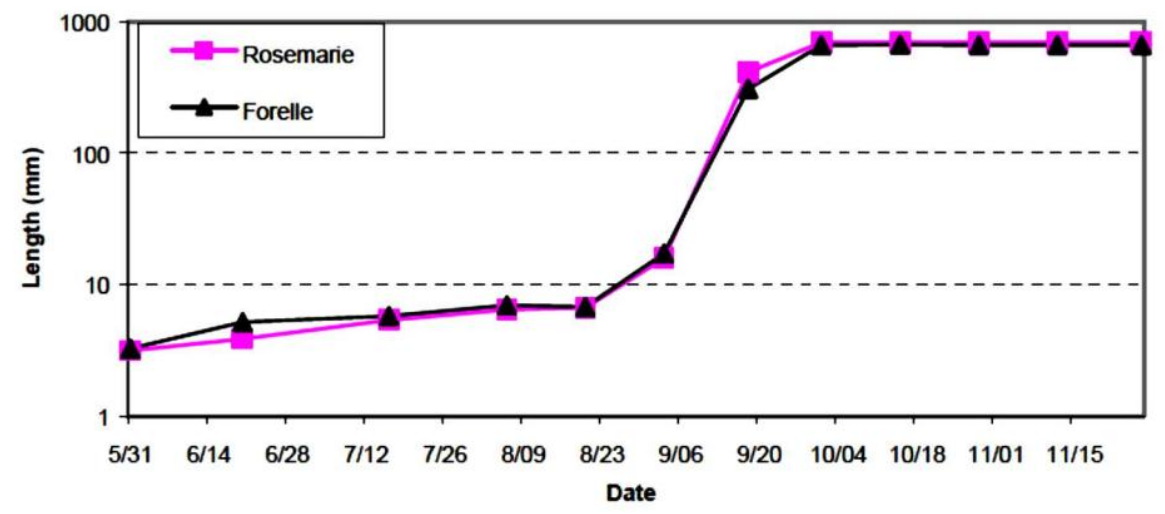

Fig. 3. Average bourse shoot outer leaf length enlargement over time. Full bloom was the $13^{\text {th }}$ and $20^{\text {th }}$ of September for 'Rosemarie' and 'Forelle' respectively.
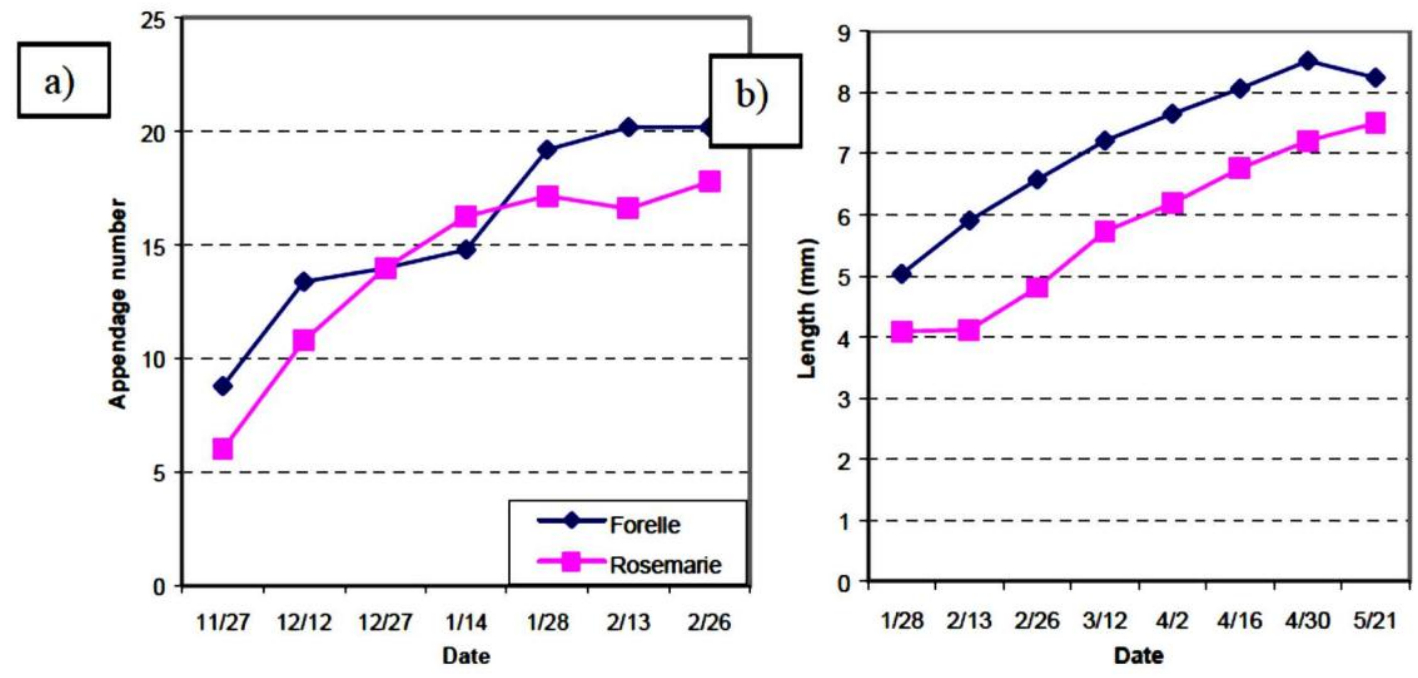

Fig. 4. (a) The average number of floral appendages of 'Forelle' and 'Rosemarie' formed during flower differentiation. (b) The length of the average flower cluster, with the bract- and transition leaves removed, for the bourse shoot's terminal reproductive bud. 